is such that even the specialist would require a reference book to understand it fully, yet the chapter on medical treatment contains long lists of presenting symptoms, a curious inclusion in a book that is likely to be read by the super-specialist.

Editorial laxity applies also to the illustrations. One plate reproducing a picture from radiotherapy planning software in black and white is rendered meaningless as the caption mentions colours. Furthermore, in the chapter on interventional radiology there are seven plates depicting the preparation of Gelfoam ${ }^{\circledR}$, a common procedure for an interventional radiologist.

The best chapters are towards the end, covering the controversial area of indications for transplantation and providing experience-based solutions to several difficult scenarios. This book will provide the hepatobiliary specialist with an upto-date and authoritative guide to the management of hepatocellular cancer.

\section{Cultivating a Thinking Surgeon: \\ New Perspectives on Clinical Teaching, Learning and Assessment}

LINDA DE COSSART, DELLA FISH

$\begin{array}{ll}\text { EXTENT P/H } & 274 \mathrm{p}, \text { paperback } \\ \text { PRICE/ISBN } & £ 35.00 \quad 1903378265 \\ \text { PUBLISHER } & \text { tfm (Shrewsbury), 2005 } \\ \text { REVIEWER } & \text { Andrew Raftery } \\ \text { STAR RATING } & * * * *\end{array}$

I like the title of this book. It presupposes that we already have a thinking surgeon, a fact that is often forgotten in this age of modernising medical careers and educational theory. The book is by two authors, one of whom is a practising surgeon and associate postgraduate dean, the other an educationalist with a background in teaching who presently holds a Chair of Education in Postgraduate Medicine.

The book is designed for both teachers and learners in surgical practice. It seeks to provide challenging new perspectives that seriously question much that the current climate of education provides, by showing examples of arguments, ideas, processes and language in which to think and talk about education rationally and logically.

It is divided into two sections: the first dealing with the educational foundation for cultivating a thinking surgeon, the second a more practical section on teaching, learning and assessing in surgical settings.
I found it very heavy reading. Much of it is written in educational jargon. The premise is that surgical teaching will have to change in the new circumstances of the 21 st century. The authors state that in the past the clinical setting was viewed as the arena in which surgeons could demonstrate clinical cases and instruct the learner in clinical and operative procedures. They feel that this approach is not commensurate with the current pressures on ways of working and that new methods and approaches to education will be required.

New models of education are presented in the first section and the chapter on 'Reflection' is very revealing educationally. The chapter includes statements such as 'having an experience is not the same as understanding its meaning' and that Habermas' work on reflection 'drives towards the ideals of empowerment and emancipation...reflection is about critique, evaluation and liberation'. I was also intrigued to learn that suitable starting points for reflection included writing a letter to a friend and experimenting with a variety of forms, e.g. prose, poetry and drama. I was sorry to see that it did not involve phoning a friend! Perhaps there is a tendency to accept that the traditional form of training provided welltrained but poorly educated surgeons. By the end of this book, I had the distinct impression that by following its recommendations we would end up with a well-educated and educationally eloquent surgeon who was poorly trained.

Somewhere among all the educational jargon is a very good book with some practical common sense. As a surgeon, I found the second section of the book much better than the first, which gave one the feel of a tree-hugging medical educationalist, with designer stubble, a suede waistcoat, cords and sandals conducting holistic teaching rather than a professional surgeon.

When I read the book, there was a certain sense of déja vu. I realised that for the past 20 years I'd actually been teaching and educating in the way outlined in this book but had not appreciated the terminology applied to my teaching methodology.

I realise now that, over those years, my trainees have reflected, conceptualised, become emancipated, developed propositional, procedural and metacognitive knowledge over the post-ward round cup of tea. This has probably been common to many surgical firms and explains why there have been such excellent and thinking surgeons produced in this country in the past.

To whom would I recommend the book? Certainly to candidates studying for a degree in medical education who will find it invaluable. It is well referenced, beautifully produced and extremely up-to-date. I would also recommend that all practising surgeons read it and form their own opinion on changes in medical education. 